\title{
THE PRODUCTION CYCLE TIME IN SERIAL PRODUCTION: REDUCTION OF THE DURATION IN METAL PROCESSING INDUSTRY CASE
}

\author{
Sanja Stanisavljev* \\ University of Novi Sad, Technical faculty "Mihajlo Pupin”, Zrenjanin, Serbia \\ Dr Dragan Ćoćkalo \\ University of Novi Sad, Technical faculty "Mihajlo Pupin”, Zrenjanin, Serbia \\ Dr Dejan Đorđević \\ University of Novi Sad, Technical faculty "Mihajlo Pupin", Zrenjanin, Serbia \\ Dr Robert Minovski \\ University of Ss. Cyril and Methodius, Faculty of Mechanical Engineering, Skopje, Macedonia
}

The most relevant factor which affects the production cycle time per unit is the size of a series. The production cycle mean value for the groups formed according to the number of units in a series $t_{p c u}$ moves along the hyperbolic function which has asymptote $c, t_{p c u}=c+b / n$, and, mathematically, these groups do not behave as strata, which means they are linked to deterministic factors of technology and number of units/series. This paper presents the application of original model on reduction in the duration of the production cycle time in serial production - research case is metal processing industry.

Key words: Production cycle time, Work sampling, Stochastic model, Serial production

\section{INTRODUCTION}

To ensure rational production and adherence to time schedules in production, quality planning of production and corresponding technicaltechnological calculations are needed to provide machine operating modes and time duration of machine operations as well as the activities in the manufacturing process. This way, they are normed, normalized and standardized, so the elements of production cycle (PC) time can be determined beforehand for machines, mechanization means and manual work. In practice they are not deterministic but stochastic, especially under conditions of small and medium businesses and as such they have to be monitored. On an experimental example Niebel [11] illustrates the determination of the elements of production cycle (PC) time, showing that production cycle $C$ is divided into only three elements of cycle time, $\mathrm{C}=\mathrm{T}_{1}+\mathrm{T}_{2}+\mathrm{T}_{3}\left(\mathrm{~T}_{1}=\right.$ running time to produce one unit of output, $T_{2}=$ normal time to service a stopped machine, $\mathrm{T}_{3}=$ time lost by normal operator working because of machine interference). The elements of PC time are possible to monitor using the work sampling method, which was originally applied in the textile industry by Tippett $[12,13,14]$, and taking into account the surveys of Barnes [01], Moder [9] and Richardson and Eleanor [11]. However, the original method has a restricted realm of use, and only three elements of PC time were monitored: the machine is in operation, the machine is in preparation, or the machine is idle $(+, x,-)$.

Although a technical-technological indicator of machine utilization level, i.e., the time of operation against machine total available time, is a very significant indicator in production and business operations and the stochastic model application itself very simple, it is more important to obtain those levels for the elements of PC time. The PC time involves the time for making a unit or a series of units from putting them in production until their storage, and aside from being significant as a technical indicator, it is important as an economic indicator of freezing current assets, especially raw materials [05]. There can hardly be any enterprise that does not monitor the PC time over documentation and analytically, but rare are those that monitor the elements of work within the PC and by analyzing those elements 
affect their reduction and thereby the PC time reduction. This is the reason why in the present paper we prove experimentally the applicability of the original stochastic method to determine the elements of PC time using as the example the results obtained by screening in metalprocessing plant with small scale production.

\section{METHODOLOGICAL OVERVIEW}

\section{The basics of a stochastic model to determine the elements of production cycle time}

The production cycle is the period from the entry of a product part or a series of products into manufacturing to their receipt in the warehouse of finished products (or parts). The production cycle is indirectly dependent on the factors of the total supply-sales cycle as its part, but some elements of cycle time are also mutually influential. For example, any increase in the supply time for parts from cooperating companies leads to a stoppage in the production cycle.

In theory, the PC time $\left(\mathrm{t}_{\mathrm{pc}}\right)$ is divided into production time $\left(\mathrm{t}_{\mathrm{p}}\right)$ and non-production time $\left(\mathrm{t}_{\mathrm{np}}\right)$ and production time is further divided into technological time $\left(t_{t}\right)$, with machine $\left(t_{t m}\right)$ and lead time $\left(t_{p f}\right)$, non-technological time $\left(t_{n t}\right)$ with time of control $\left(\mathrm{t}_{\mathrm{c}}\right)$, transportation $\left(\mathrm{t}_{\mathrm{tr}}\right)$ and packaging $\left(\mathrm{t}_{\mathrm{pk}}\right)$. Nonproduction time is classified according to various causes of stoppages in production, and we have made the screening of the most general and common ones caused by the lack of raw materials $\left(t_{m r}\right)$, tools $\left(t_{t}\right)$, organization $\left(t_{0}\right)$, machine breakdown $\left(t_{b}\right)$ and other troubles $\left(t_{o t}\right),[02,03]$.

Our investigation is directed at designing a new original method for monitoring the production cycle and its time elements by using a stochastic work sampling method, whose basis was set up by Tippett. However, this method will be innovated and adapted to an investigation of the production cycle.

A modified work sampling method will enable the determination of the participation percentages of working time elements against the total duration of the production cycle and production. As this method is statistic and is based on a certain number of instantaneous observations of a certain activity, it is simpler to use and more efficient than the continual streaming method. Monitoring within the production cycle will involve technological time with lead time and manufacturing time, non-technological time with times for transport, control and packing, while non-production time includes stoppage due to poor production organization, lack of materials, lack of tools, including the failure or breakdown of machinery and other types of stoppage, their interdependence, as well as impact factors such as series size, organizational level and product characteristics pertaining to the factors mentioned.

\section{Establishing the representativeness of screening time duration}

Representative screening time is related to the length of the production cycle time. It is clear that it must not be shorter than the production cycle time and that under identical production conditions it must be repeated a certain number of times in order to make the sample representative. Production and productivity are also related to the production dynamics which are planned at the operational level on a daily, weekly or monthly basis. Hence, the production cycle for the above mentioned periods is also provided for the purposes of monitoring and comparing. The third criterion for determining screening time duration is the adopted margin of error in the stochastic model applied in these investigations, i.e. the number of instantaneous observations and their distribution per working time element.

\section{The problem of determining technological time}

Screening performance requires the precise definition not only of technological and mathematical problems, but also of the practical screening process and the establishment of working time elements. Thereafter, the elements of production cycle working time should be defined and, in particular, the difference against the elements of working time related to machinery, i.e. for the purpose of establishing the machine capacity only or within the production cycle, because these two are not the same. The elements of working time are determined according to Barnes [01], Maynard [08], Moder [09], Niebel [10], Richardson and Eleanor [11], Klarin et al. [07] and Čala et al. [03]. Theoretically speaking, the sequence of operations may be serial, parallel or combined. Therefore, depending on the type of sequence of operations, we know in advance that this portion of cycle time lasts much longer in a serial type, where before moving on to the next operation the whole series waits to be completed by a single machine operation, while in a parallel type, after 
one machine part is completed on one machine, it immediately moves on to the next. In companies, the most common type of sequence of operations is combined. Not infrequently, one part of the production cycle is parallel, another serial, and a third combined. Technological machine time $\left(t_{t m}\right)$, viewing production against machinery, is exclusively linked to machine performance and the quality of technological calculations, and is mainly a deterministic category. However, if the production cycle is viewed from the aspect of a serial sequence of operations, the elements of working time differ, depending on the automation level. If production is automated, then ttm for a series will be simply a sum of individual $n$ equal operations. However, if each part has to be manually or mechanically conveyed for processing from a joint crate or some other room where a certain series of parts is stored, manual placement on the machine is ancillary manual time $\left(t_{p r}\right)$. In theory, this refers to individual pieces. Such time is not frequently encountered in literature (rear examples are papers, [06] and [07]) dealing with the division of working time elements. In our investigations, ancillary manual time will be treated as technological machine time $\left(t_{t m}\right)$. It is also logical to add ancillary machine time (for example, support moving a lathe) to $\left(t_{t m}\right)$. Manufacturing lead time includes receipt of work order with documentation and study of tasks, receipt of equipment, preparation of other components necessary for work, transport of finished pieces for quality control and cleaning up of work place, after a certain number of pieces (n) are manufactured, one at a time, non-stop (number of pieces in a series).

\section{APPLICATION OF THE MODEL}

The practical application of establishing the mentioned elements of PC time is reduced to instantaneous observations of time elements, where the object of labor moves through the production operations list. A series of units is distinctly marked by this document and an analyst (recorder) can readily identify it. Production cycle is calculated differently depending $n$ type of operations sequence.

\section{Results before model application}

The first most extensive experiment concerns an enterprise owned by a large German firm engaged in manufacturing car components. Screenings were performed from September 19, 2011 to November 4, 2011. Monitoring included 47 cycles of different series sizes ( $4-10$ units) and the time duration ranged from the shortest $(240 \mathrm{~min})$ to the longest (420 $\mathrm{min}$ ), with 10 - 30 instantaneous observations. There were 932 observations in total, while the total time for all cycles amounts to $15,293 \mathrm{~min}$. The average production cycle time - tpc is $325 \mathrm{~min}$ and the average production cycle time per unit tpc is $56.2 \mathrm{~min}$.

Investigations related to the coefficient of running time as a function of the series size and where the PC was analytically monitored from the plant's records did not include an in-depth analysis of the relationships between the series. Data for all cycles elements calculated as percents of cycle time are shown on Figure 1. The mean value for all the groups with the same number of units in a series obtained is $\bar{t}_{p}=74.35 \%$ and rangesfrom the bottom control limit $B C=52.64 \%$ to the upper control limit $A C=96.06 \%$.

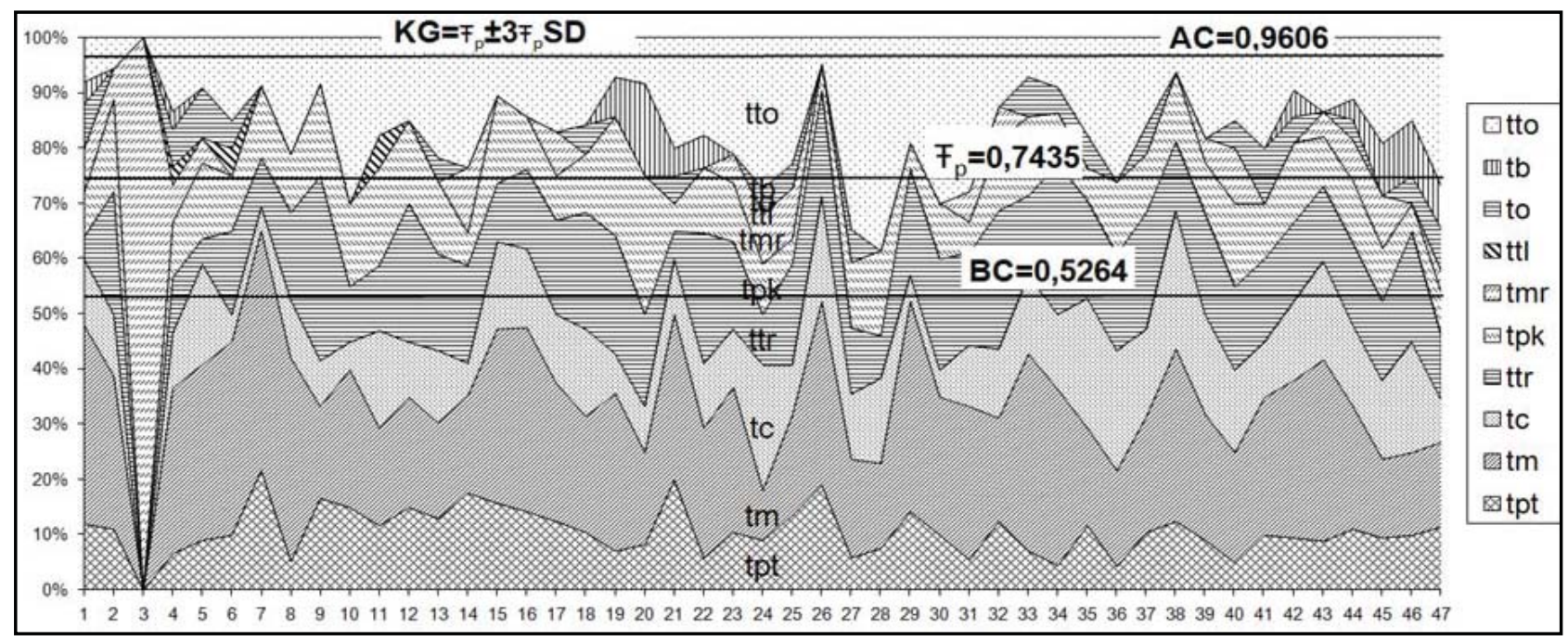

Figure 1: Data for production cycles elements monitored in 2011 
Table 1: Number of cycles and number of units in a series for enterprise I in 2011

\begin{tabular}{|c|c|c|c|c|c||}
\hline \multirow{2}{*}{ No } & No of cycle & unit/ser & $\bar{t}_{p c u}$ & & \\
& & & & $\overline{\bar{t}}_{p}(\%)$ & $\mathrm{SD}_{\mathrm{tp}}$ \\
\hline 1 & 3 & 3 & 93.10 & 85.41 & 7.42 \\
\hline \hline 2 & 4 & 4 & 72.48 & 81.31 & 16.14 \\
\hline \hline 3 & 18 & 5 & 63.29 & 74.97 & 28.04 \\
\hline \hline 5 & 10 & 6 & 57.02 & 70.84 & 29.64 \\
\hline \hline 6 & 3 & 7 & 43.50 & 76.67 & 16.91 \\
\hline \hline$\overline{\bar{t}}_{p}(\%)$ & 3 & 8 & 45.50 & 77.78 & 10.07 \\
\hline \hline
\end{tabular}

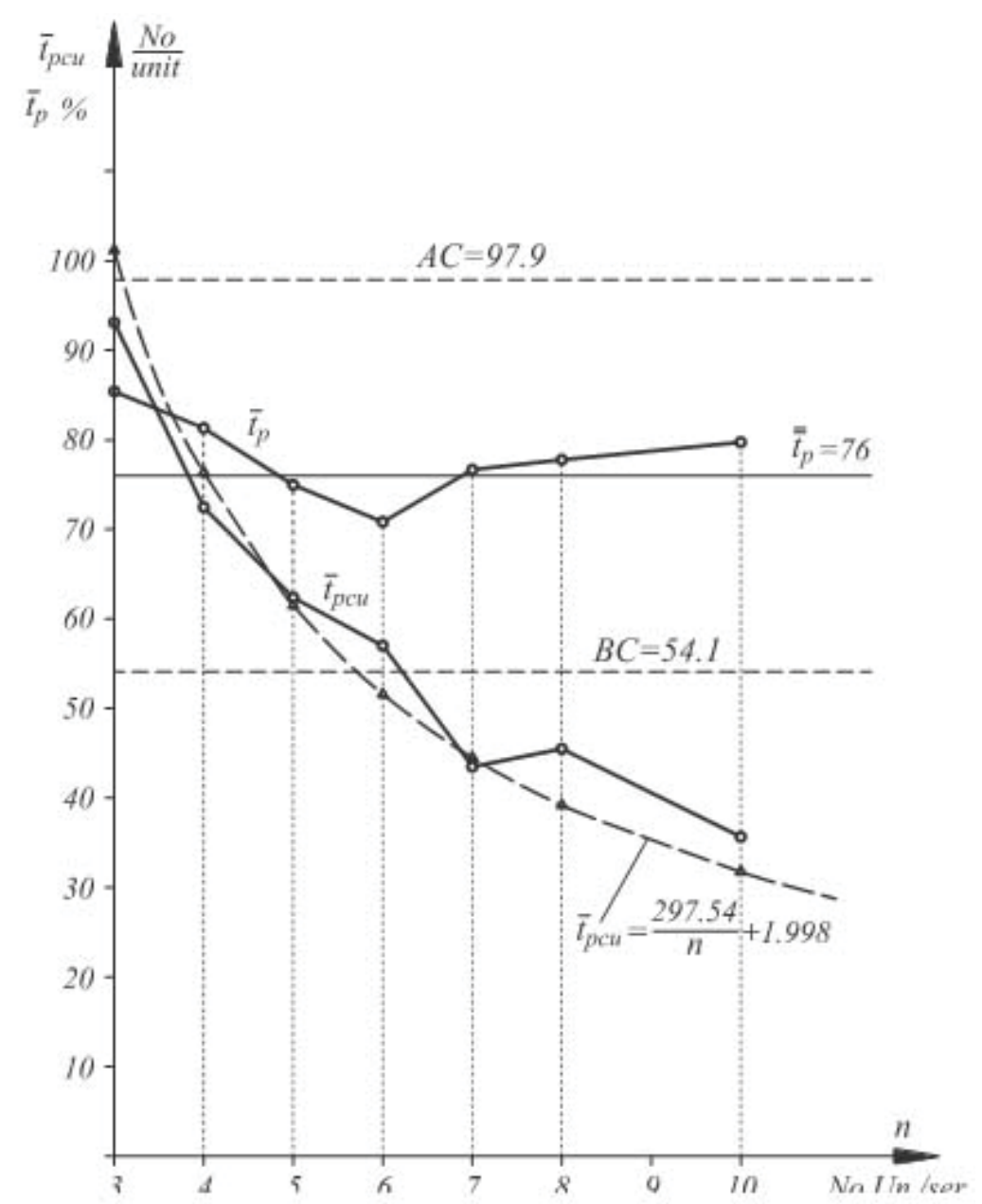

Figure 2: Trends of production time tp mean values and PC mean values per unit in a series $t_{p c u}$ in 2011

Table 1 displays the same data without the groups but with the number of screening cycles and the number of units in those cycle series, with the total mean value of the PC time $-\bar{t}_{p} \%$ that amounts to $76 \%$. The trends of PC time mean values $\bar{t}_{p}$ by cycles (groups) with an identical number of units in a series in \% and the PC mean values per unit in a series $\bar{t}_{c}$ are given in the diagram in Figure 2. The mean value for all groups is obtained using the formula: 


$$
\overline{\bar{t}}_{p}=\sum \frac{\bar{t}_{p i} \cdot f_{i}}{N}
$$

where $f_{i}$ is the number of PCs with an identical number of units in a series $\overline{\bar{t}}_{p}=\frac{85,41 \cdot 3}{46}+\ldots+\frac{79,75 \cdot 3}{46}=76 \%$ for a non-stratified set of data from Table 1, using formula 2:

$$
\mathrm{SD}_{\mathrm{p}}^{2}=\frac{\sum_{\mathrm{j}=1}^{\mathrm{l}}\left(\overline{\mathrm{t}}_{\mathrm{pi}}-\overline{\overline{\mathrm{t}}}_{\mathrm{p}}\right)^{2} \mathrm{n}_{\mathrm{j}}}{\mathrm{n}}
$$

where $n$ is the number of cycles in a group and $\mathrm{n}$ is the total number of cycles:

$$
C C=\overline{\bar{t}}_{p} \pm 3 \overline{\bar{t}}_{p} S D_{p}
$$

$\mathrm{CC}=76 \pm 3 \cdot 0.09606 \cdot 76$

$A C=97.9 \%$

$\mathrm{BC}=54.1 \%$

It is obvious from the diagram in Figure 2 that mathematically viewed the process is mastered, because all the points of lie within the control limits $\mathrm{BC}<\bar{t}_{p_{i}}<\mathrm{AC},(54.1<76<97.9)$.

The trend of $\bar{t}_{p_{i c u}}$ can be approximated by the function:

$$
\bar{t}_{p c u}=c+\frac{b}{n}
$$

where $\mathrm{n}$ is the number of units, and in enterprise $\mathrm{I}, \mathrm{C}=1.998$ and $\mathrm{b}=297.54$.
A statistical set stratification has not been successful because the SD of a stratified set is:

$$
\sigma^{\prime}=\sqrt{\bar{\sigma}^{2}+\delta^{2}}
$$

$$
\sigma^{\prime}=27.19 \%
$$

$$
\begin{aligned}
& S D=\sqrt{\left(t_{p i}-\bar{t}_{p}\right)^{2}} \\
& \bar{\sigma}^{2}=\frac{\sum_{j=1}^{l} \sigma_{j}^{2} n_{j}}{n} \\
& \delta^{2}=\frac{\sum_{j=1}^{l}\left(\bar{t}_{p}-\overline{\bar{t}}_{p}\right)^{2} n_{j}}{n} \\
& S D_{p}=9.606 \%
\end{aligned}
$$

Since $\mathrm{SD}<\bar{\sigma}^{\prime}$ the stratification was unsuccessful, which means that in this enterprise there is no feature distinguishing the PC with a different number of units in a series, but the reduction of time per unit is exclusively the result of technological time, i.e. the elements of working time and the number of units.

\section{Results after model application}

In 2012, after model initial application, experiment is again conducted in 2012 to check if there are some improvements in production cycle elements.

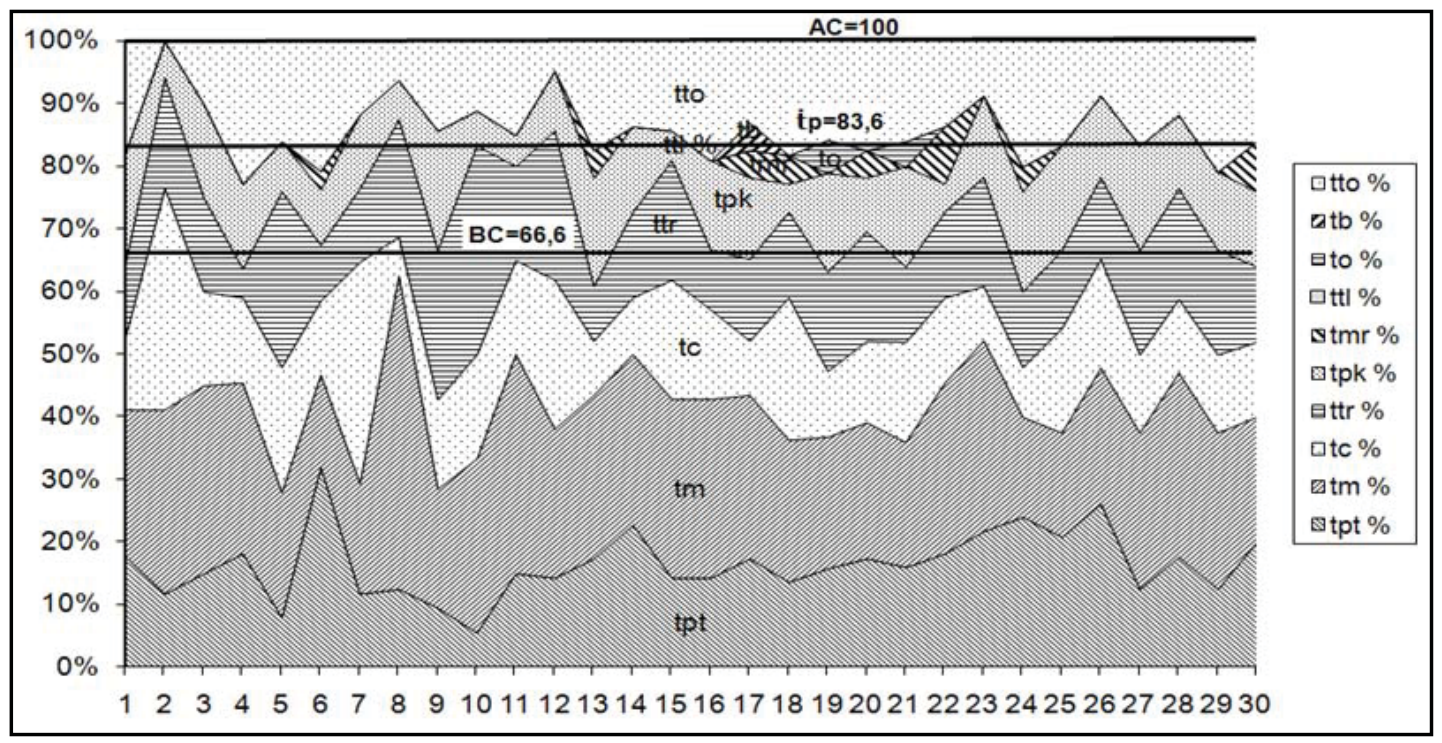

Figure 3: Data for all cycles elements monitored in in 2012

In enterprise I screenings were carried out again from $23^{\text {rd }}$ October to $2^{\text {nd }}$ November, 2012. Monitoring comprised 30 production cycles, with 17 to 26 instantaneous observations, with mean value
21 and 644 observation in total. Data on production cycle elements collected in enterprise I in 2012 are shown on Figure 3. 
Table 2: Number of cycles and number of units in a series for enterprise I in 2012

\begin{tabular}{|c|c|c|c|c|}
\hline No & No of cycle & unit/ser & $\bar{t}_{\text {pcuser }} \mathrm{min} / \mathrm{unit} / \mathrm{ser}$ & $\bar{t}_{p(\%)}$ \\
\hline 1 & & & 48 & 85.71 \\
\hline 2 & & & 51 & 78.26 \\
\hline 3 & & & 62 & 76 \\
\hline 4 & $\bar{x}$ & 3 & 53.7 & 80 \\
\hline 5 & & & 43.2 & 82.35 \\
\hline 6 & & & 43.2 & 100 \\
\hline 7 & & & 35.6 & 90 \\
\hline 8 & & & 56.8 & 77.27 \\
\hline 9 & & & 38.8 & 84 \\
\hline 10 & & & 41.8 & 93.75 \\
\hline 11 & & & 41.8 & 85 \\
\hline 12 & & & 41.8 & 95.24 \\
\hline 13 & & & 47.6 & 86.36 \\
\hline 14 & & & 49.8 & 78.26 \\
\hline 15 & & & 47 & 77.27 \\
\hline 16 & & & 40.5 & 88.24 \\
\hline 17 & $\overline{\mathrm{x}}$ & 12 & 32.3 & 86.5 \\
\hline 18 & & & 40 & 86.66 \\
\hline 19 & & & 40.7 & 80.95 \\
\hline 20 & & & 40.8 & 83.33 \\
\hline 21 & & & 38.5 & 79.17 \\
\hline 22 & $\bar{x}$ & 4 & 34.3 & 82.5 \\
\hline 23 & & & 23.8 & 69.23 \\
\hline 24 & & & 23.8 & 85.71 \\
\hline 25 & & & 31.3 & 88.89 \\
\hline 26 & & & 31.6 & 77.27 \\
\hline 27 & & & 31.6 & 78.95 \\
\hline 28 & & & 31.6 & 80 \\
\hline 29 & $\bar{x}$ & 6 & 30.1 & 80 \\
\hline 30 & & 1 & 30.6 & 78.26 \\
\hline 31 & & 1 & 31.7 & 83.33 \\
\hline 32 & & & 30.4 & 91.3 \\
\hline 33 & & & 27.5 & 91.3 \\
\hline 34 & $\bar{x}$ & 2 & 29 & 91.3 \\
\hline 35 & & 1 & 27.6 & 75 \\
\hline$\Sigma$ & & & 281.7 & 656.89 \\
\hline
\end{tabular}

$$
\bar{t}_{p}=82.33 \%, \bar{t}_{p c u s e r}=37.7 \mathrm{~min}
$$


Time durations were 233 minutes as average value, while one year later, before model application, it was 325 minutes. The mean value for all the groups with the same number of units in a series obtained is $\bar{t}_{p}=83.60 \%$ and ranges from the bottom control limit BC $=66.66 \%$ to the upper control limit $A C=100 \%$. It can be seen that production cycle time after model application is $28 \%$ reduced, while average cycle time is reduced from 35 to 17 minutes. Trends of production time $t_{p}$ mean values and PC mean val- ues per unit in a series $t_{p c u}$ for enterprise I now have different coefficients $c=-7.363$ and $b=239$, as can be seen on Figure 3 and Table 2 .

The trend in production time by strata by the number of units in a series of tables 1 and 2 and the diagrams in Figures 2 and 4 shows that there was a significant reduction in production time duration in minutes of $\bar{t}_{\text {pcuser }}=52.389,2011$. years to $\bar{t}_{\text {pcuser }}=37.7$ for 2012 . as a result of the stochastic model of research production cycle.

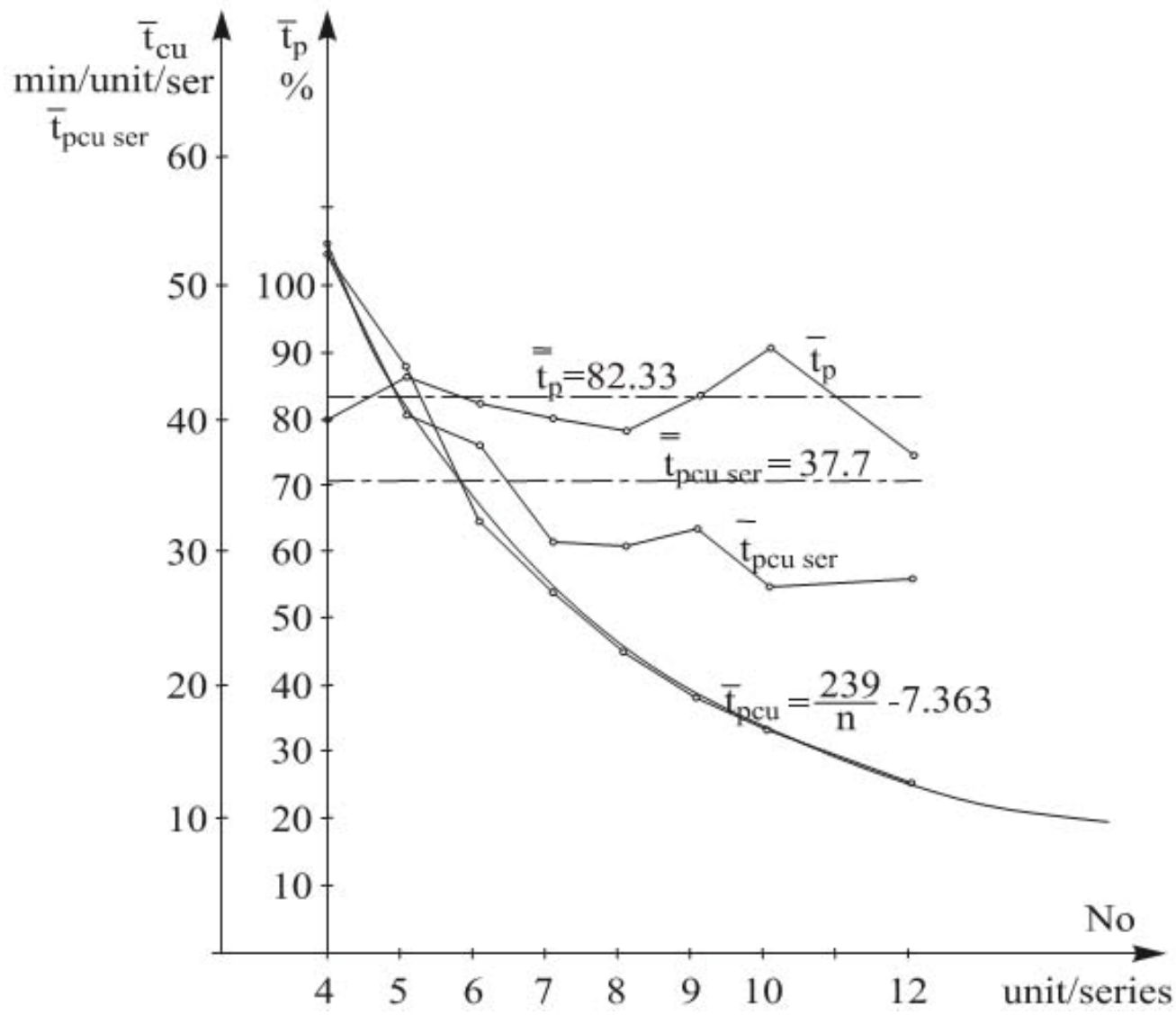

Figure 4: Trend of production time $t_{p}$ mean values and $P C$ mean values per unit in a series $t_{p с u}$ in 2012.

\section{CONCLUSION}

The original method for determining the elements of production cycle time using a modified work sampling method was proved through experimental investigations done in 2011 and 2012, which involved a large number of Serbian enterprises. Results have shown that the production process is mastered through model application. The most relevant factor which affects the production cycle time per unit $-t_{p c u}$ is the size of a series.

- By applying stochastic model of research production cycle in a representative plant showed a significant reduction in the duration of the production time in minutes from $\bar{t}_{\text {pcuser }}=52,389$ in 2011. years to $\bar{t}_{\text {pcuser }}=$ 37 in 2012.

- The PC mean value for the groups formed according to the number of units in a series tpcu moves along the hyperbolic function which has asymptote $\mathrm{C}, t_{p c u}=\mathrm{C}+\mathrm{b} / \mathrm{n}$, and, mathematically, these groups do not behave as strata, which means they are linked to deterministic factors of technology and number of units/series. 
- The process is mastered to a higher degree when all levels of working time elements are utilized to a higher degree (or \%) and production time tp is the most important for the process. This means that it is more favourable to apply higher organizational and production levels in the stochastic model for establishing the elements of PC time;

- In experiments to follow optimization is needed for the number of working time elements and stoppages depending on the type of production.

\section{REFERENCES}

1) Barnes, R. (1957). Work Sampling, 2 nd edn. New York: Wiley.

2) Brkić-Spasojević, V., Klarin, M., \& Curović, D. (2009). Dimenzije menadžmenta kvalitetom isporučioca u industrijskim preduzećima Srbije. Journal of Applied Engineering Science, 7(23-24), 67-71.

3) Čala, I., Klarin, M., \& Radojčić, M. (2011). Development of a Stohastic model for determing the elements of production cycle time and their optimization for serial production in Metal processing industry and recycling processes. Journal of Engineering Management and Competitiveness (JEMC), 1(1-2), 21-25.

4) Elnekave, M., \& Gilad, J. (2006). Rapid video-based analysis for advanced work measurment. Int. Journal of Production research, 44(2), 271-290.

5) Jovanovic, J., Milanovic, D., Radovic, M., \& Đukic, R. (2012). Investigations of Time and Economic Dimensions of the Complex Product Production Cycle. Journal of Applied Engineering Science, 10(3), 153-160.

6) Klarin, M.M., Cvijanović, M.J., \& SpasojevićBrkić, K.V. (2000). The shift level of the utilization of capacity as the stochastic variable in work sampling. International Journal of Production Research, 38(12), 2643-2651.

7) Klarin, M.M., Milanović, D.D., Misita, M., Spasojević-Brkić, K.V., \& Jovanović, A. (2010). A method to assess capacity utilization in short cycle functional layouts. Proceedings of the Institution of Mechanical Engineers Part E-Journal of Process Mechanical Engineering, 224(E1), 49-58.

8) Maynard, H.B. (1971). Industrial Engineering Handbook. Pittsburgh. PA: McGraw-Hill.
9) Moder, J.J. (1980). Selection of work sampling observation times - Part I: Stratified sampling. AlIE Transactions, 12 (1), 23-31.

10) Niebel, W.B. (1980). Time Study, Handbook of Industrial Engineering. Salvendy G. (Eds). New York: Wiley.

11) Richardson, W.J., \& Eleanor, S.P. (1982). Work Sampling, Handbook of Industrial Engineering, Salvendi G. (Eds.). New York: Wiley

12) Tippett, L.H.C. (1929). Statistical Methods in Textile Research: The Analysis od Complex Variations. Shirley Institute Memoirs, 8, 175190.

13) Tippett, L.H.C. (1935). Some Applications of Statistical Methods to the Study od Variation of Quality in the Production of Cotton Yam. Supplement to the Journal of the Royal Statistical Society, II, 27-62.

14) Tippett, L.H.C. (1936). Applications of Statistical Methods to the Control of Quality in Industrial Production. Transactions of the Manchester Statistical Society, 1-32.

\section{ACKNOWLEDGEMENTS}

This paper was supported by the Serbian Ministry of Education and Science, Grant TR 35017.

Paper sent to revision: 01.07.2013.

Paper ready for publication: 29.08.2013. 